\title{
EXPERIMENTAL MURINE CHROMOBLASTOMYCOSIS OBTAINED FROM Fonsecaea pedrosoi ISOLATE CULTURED FOR A LONG PERIOD
}

\author{
Machado AP (1), Freymuller E (2), Fischman O (2)
}

(1) Department of Basic Health Sciences, Federal University of Mato Grosso, Cuiabá, Mato Grosso State, Brazil; (2) Department of Microbiology, Immunology and Parasitology, Federal University of São Paulo, UNIFESP, São Paulo State, Brazil.

\begin{abstract}
The present study aimed to describe $F$. pedrosoi propagules capable of causing chronic murine disease. Several changes in F. pedrosoi hyphae were identified in fungal cells cultured for a long period. Optical microscopy found many rounded cells with double-rigid melanin-rich walls. Terminal and intercalary chlamydoconidia were also frequently observed. Analyses of images from transmission electron microscopy (TEM) revealed several cells with walls composed of at least three layers and an outer layer enriched with melanin. Two groups of twenty BALB/c mice were subcutaneously infected in their footpads with $F$. pedrosoi cells at an inoculum concentration of approximately $1 \times 10^{4}$ cells $/ \mathrm{mL}$. In one group, long-term cultured $F$. pedrosoi cells were inoculated in one footpad, whereas in the other group, both footpads were infected. Active lesions were observed up to seven months post-infection, particularly in mice inoculated at two sites. After this period, animals were killed. Histological sections revealed characteristics bearing a strong resemblance to the human form of the disease such as tissue hyperplasia, granulomas with microabscesses and sclerotic cells. Based on this study, we identified fungal cells from old cultures capable of provoking chronic chromoblastomycosis under experimental conditions, especially when more than one site is infected.
\end{abstract}

KEY WORDS: Fonsecaea pedrosoi, experimental chromoblastomycosis, sclerotic cells.

CONFLICTS OF INTEREST: There is no conflict.

FINANCIAL SOURCE: CNPq.

\section{CORRESPONDENCE TO:}

ALEXANDRE PAULO MACHADO, Laboratório de Microbiologia, Departamento de Ciências Básicas em Saúde, Faculdade de Ciências Médicas, Universidade Federal de Mato Grosso, Avenida Fernando Corrêa, s/n, Coxipó, Cuiabá, MT, 78060-900, Brasil. Phone: +55 653615 8835. Email: alexandre.paulo@unifesp.br or alepaulo@hotmail.com. 


\section{INTRODUCTION}

Chromoblastomycosis (CBM) is a chronic human disease caused by several dematiaceous fungal species, of which Fonsecaea pedrosoi and Cladophialophora carrionii are the most common throughout the world $(1,2)$. CBM therapy has produced limited success, especially in severe clinical forms $(1,3)$. Therefore, finding a suitable model for chronic experimental CBM is important for studying the immunological response and testing novel antifungal drugs. The presence of parasitic forms normally known as sclerotic (fumagoid or muriform) cells (also known as Medlar bodies) in tissues is a typical sign of the human form of the disease $(2,4)$. However, the fungal forms involved in establishing the infection and the mechanism of their adaptation to parasitism remain unknown.

Fungal cell modifications most often occur as resistance to chemical, biological and physical stress conditions. Fungal cells similar to the parasitic forms found in CBM can be induced in vitro under acidic conditions with low calcium concentration (5-7). Still, the infective potential of these forms requires further experimental study. The fungal cell alteration into sclerotic forms has been proposed as a virulence factor (6, 8). Sclerotic cells were detected in environmental samples of vegetables, suggesting the possible existence in natura of forms pre-adapted to parasitism $(6,8,9)$. Recently, artificial inoculations of $C$. carrionii in cactus tissue revealed a morphological resemblance between sclerotic bodies and meristematic cells formed after vegetable transience (10).

Although hyphae and conidia are currently cited in the literature as potentially infectious in humans, several studies are have failed to reproduce a long-term stable chronic infection with these forms cultured in agar or broth for periods of 15 to 30 days (11-17). Fungal infections comprised of young culture forms at a single site generally produce acute inflammatory reactions mediated mainly by neutrophils, with animals healing within two months, independently of the infection site or inoculum concentration $(11,13,14,16-18)$.

Increased persistence of $F$. pedrosoi infection was found in animals inoculated at more than one site (16). A link between suppressor T cells and peripheral tolerance induced after Leishmania major inoculation at two sites has been described $(19,20)$. In our previous experiments, we observed that inoculation at two sites with 30-dayold forms is sufficient to cause this persistent infection. However, the infection sites in 
most animals healed within 3 to 4 months post-inoculation and did not develop a stable chronic infection.

Therefore, the present study aims to describe the morphology of $F$. pedrosoi forms obtained from old cultures, and the ability of these fungal cells to provoke infection in laboratory mice inoculated at one or two sites.

\section{MATERIALS AND METHODS}

\section{Fonsecaea pedrosoi Isolate}

A Fonsecaea pedrosoi strain (EPM - 380/03) provided from a patient with CBM examined in 2003 in the Dermatology Outpatient Department, UNIFESP, was cultured on Sabouraud dextrose agar (SDA, Difco Laboratories, USA) supplemented with $80 \mathrm{mg} / \mathrm{L}$ of gentamycin (Schering-Plough, USA) at $28^{\circ} \mathrm{C}$. The fungal strain employed in this study was preserved in sterile distilled water inside sealed penicillin tubes by the method of Castellani and maintained at room temperature. Aliquots containing fungal cells were collected using a sterilized insulin needle for cultivation.

\section{Culture}

The F. pedrosoi strain was cultured in $1 \mathrm{~L}$ cylindrical glass bottles (Kimax® GL-45, Daigger Lab Equipment and Supplies, USA) containing $300 \mathrm{~mL}$ of Sabouraud dextrose broth (SDB, Difco Laboratories, USA) with gentamycin, $\mathrm{pH} 5.7$, at $28^{\circ} \mathrm{C}$ in a incubator $(T E-420 \AA$, Tecnal, Brazil) and shaken at 100 rpm for six months.

\section{F. pedrosoi Cells}

Cultures of F. pedrosoi were vortexed and filtered through sterile gauze to retain macroscopic fungal balls and mycelial aggregates. Filtrates were drawn up into a 50 $\mathrm{mL}$ glass needle and ejected into a beaker several times to disrupt small mycelia clusters and to obtain solitary cells and small fragments of hyphae. Cells were then recovered by centrifuging homogenates at $3000 \mathrm{~g}$ for ten minutes and subsequently observed by optical microscopy. Images were captured using a Q-Color5® digital camera fitted to an Olympus BX50® microscope (Olympus Optical Co. Ltd., Japan). Images were processed using Image Pro Express ${ }^{\circledR}$ software (version 6.3, Media Cybernetics, USA). Samples from old cultures were cultivated on blood agar and stored at $28^{\circ} \mathrm{C}$ for bacterial contamination tests. 


\section{Transmission Electron Microscopy (TEM)}

For TEM, F. pedrosoi cells cultured for six months were fixed for two hours at room temperature with $3 \%$ glutaraldehyde and $4 \%$ formaldehyde in $0.1 \mathrm{M}$ cacodylate buffer, $\mathrm{pH}$ 7.2. Fixed cells were washed in cacodylate buffer three times for 30 minutes (each wash) and once overnight, and then fixed for two hours with $2 \%$ osmium tetroxide in $0.1 \mathrm{M}$ cacodylate buffer. Cells were subsequently washed with $0.1 \mathrm{M}$ cacodylate buffer three times for 15 minutes, then gradually dehydrated in a series of ethanol solutions and embedded in Eppon resin. Ultrathin sections were mounted on Formvar grids, stained with 4\% uranyl acetate and lead citrate, and observed under a transmission electron microscope (JEOL 1200 EX II®, USA) at 80 kV (21). Note: materials cited for TEM were purchased from Electron Microscopy Sciences Company (USA).

\section{Inocula}

Inoculum viability was assessed using LIVE/DEAD® Cell Vitality Assay kit (L34951, Invitrogen, USA) in fluorescent microscopy. Suspensions containing fungal forms were adjusted to a concentration of $1 \times 10^{4} \mathrm{cells} / \mathrm{mL}$ in a Neubauer chamber. The minimal concentration of the fungal inoculum for animal infection was standardized by a pilot study. Short hyphal fragments had approximately six to ten septa. The separation among septa was employed to distinguish individual hyphal cells that were then counted. The inocula population contained a cellular mix of approximately $23 \%$ solitary chlamydoconidia cells, $18 \%$ roundish cells, $26 \%$ conidia, and $33 \%$ hyphal fragments. The suspension had a viability of approximately more than $95 \%$ of total cells.

\section{Infection}

Two groups of $20 \mathrm{BALB} / \mathrm{c}$ male mice weighing approximately $23 \mathrm{~g}$ each (6 to 8 weeks old) were used throughout the study. These pathogen-free animals were purchased from CEDEME/UNIFESP (São Paulo, Brazil). The protocol employed herein was approved by the UNIFESP Ethics Committee (project number 0808/05). Ten minutes prior to infection, animals were intraperitoneally anesthetized with $0.4 \mu \mathrm{L}$ Anasedan ${ }^{\circledR}$ and $0.35 \mathrm{~mL} / \mathrm{kg}$ Dopalen ${ }^{\circledR}$ (both from Vetbrands, Brazil). Approximately $50 \mu \mathrm{L}$ of the $F$. pedrosoi cell suspension was inoculated subcutaneously into the footpads (about 500 cells/footpad). Swelling was monitored every 30 days up to a 
maximum of seven months using a Mitutoyo digital caliper (USA). Footpad volume was calculated based on height and width measurements and the mathematical formula for a cylinder volume. Results are expressed as mean \pm SE. Based on normality data as defined by the D'Agostino and Pearson omnibus test, significant differences were determined using an ANOVA test (Prism software). Seven months after infection, mice were killed and their footpads were removed in accordance with guidelines on the use and care of laboratory animals (22-24). A sample of infected tissue was analyzed and cultivated on SDA. Fresh tissue samples were clarified with $20 \% \mathrm{KOH}$ and examined directly by optical microscopy.

\section{Histopathology}

Tissue specimens were left in 10\% formalin for over 12 hours. Bone tissue from the paws was decalcified with $5 \%$ ethylenediaminetetraacetic acid (EDTA, SigmaAldrich, USA) (17). The specimens were embedded in paraffin, and 3 to $5 \mu \mathrm{m}$ serial sections from the blocks were stained with hematoxylin-eosin (Sigma-Aldrich, USA) and periodic acid-Schiff (PAS, Merck Chemicals, Germany).

\section{RESULTS}

\section{Light Microscopy and TEM}

Different morphological forms were found through optical microscopy. There were spherical or ovoid-shaped cells and hyphae with intercalary or terminal chlamydoconidia shapes. In general, these forms were $5 \mu \mathrm{m}$ to $20 \mu \mathrm{m}$ in diameter, sometimes with planate divisions and a large nucleus (Figure 1). A significant number of cells were more pigmented than others (Figure 2). By TEM, we verified that cell walls of these forms were composed of a thick multilayer containing at least three layers (Figure 3). The outer layer had a dark, electron-dense appearance, and was probably comprised of melanin (Figure 3D). Bacterial contamination was not detected in samples taken from old cultures. 

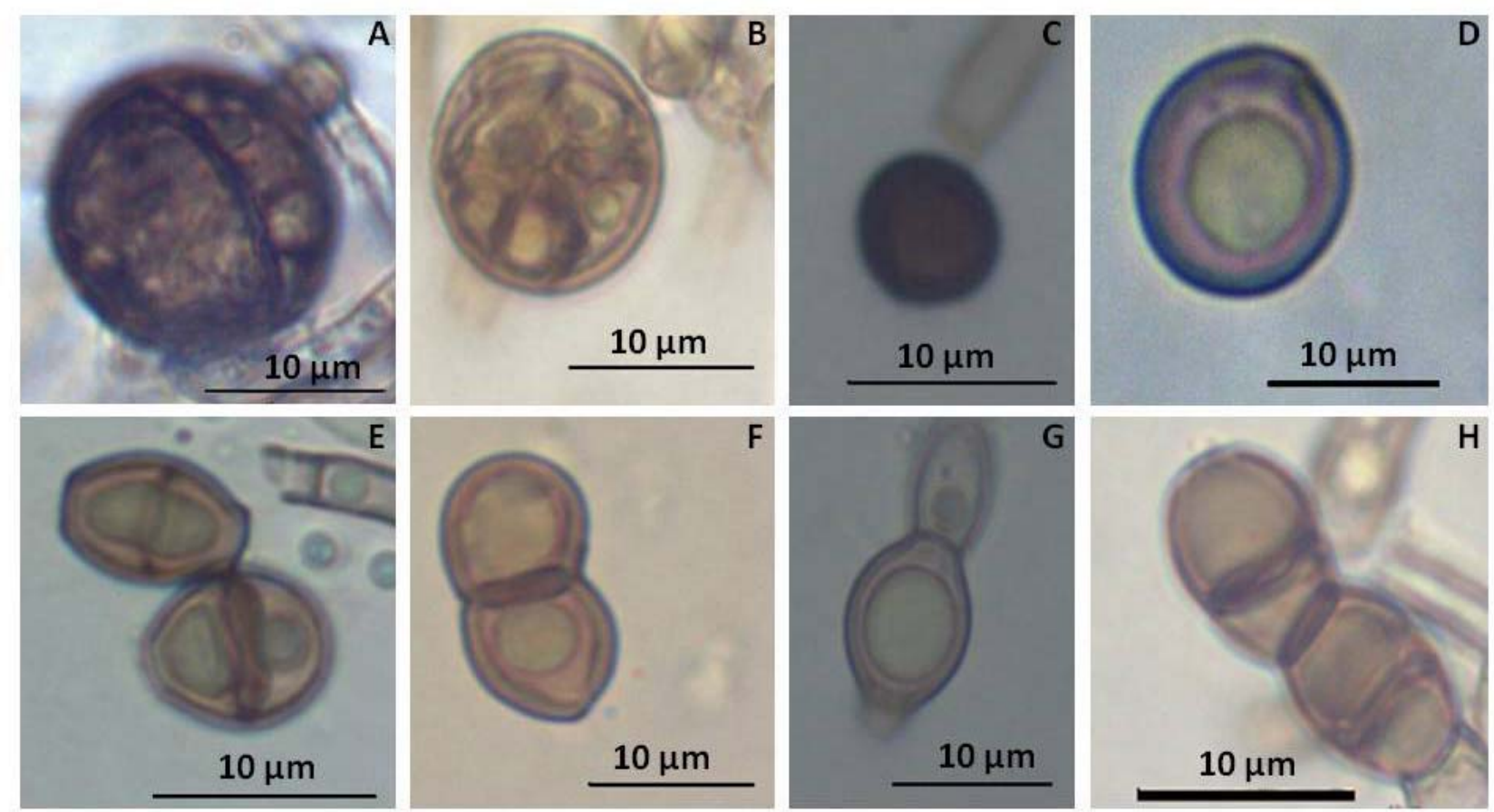

Figure 1. Highly melanized fungal forms with diameters ranging from 5 to $20 \mu \mathrm{m}$ from pure cultures of $F$. pedrosoi cultivated for six months (1000x). (A and B) Multicellular and (C and D) unicellular chlamydoconidia; $(\mathbf{E}-\mathrm{H})$ roundish cells.

* Many cells have an enlarged nucleus (light green).

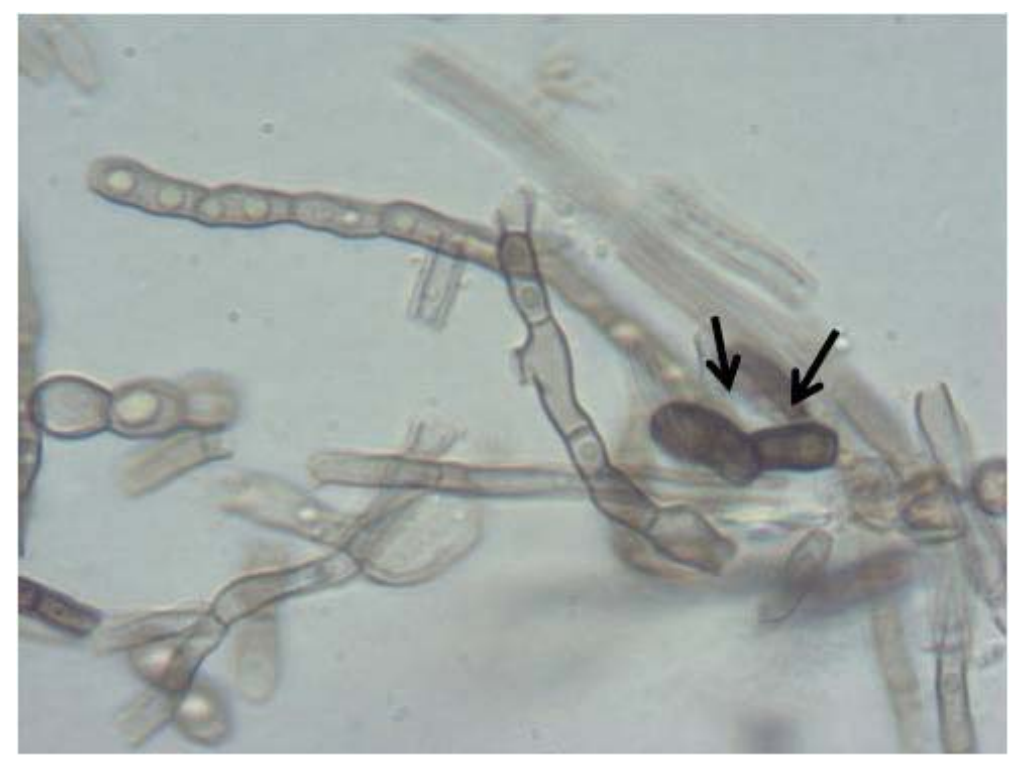

Figure 2. Highly melanized hyphal cells from F. pedrosoi cultured for six months (400x). 

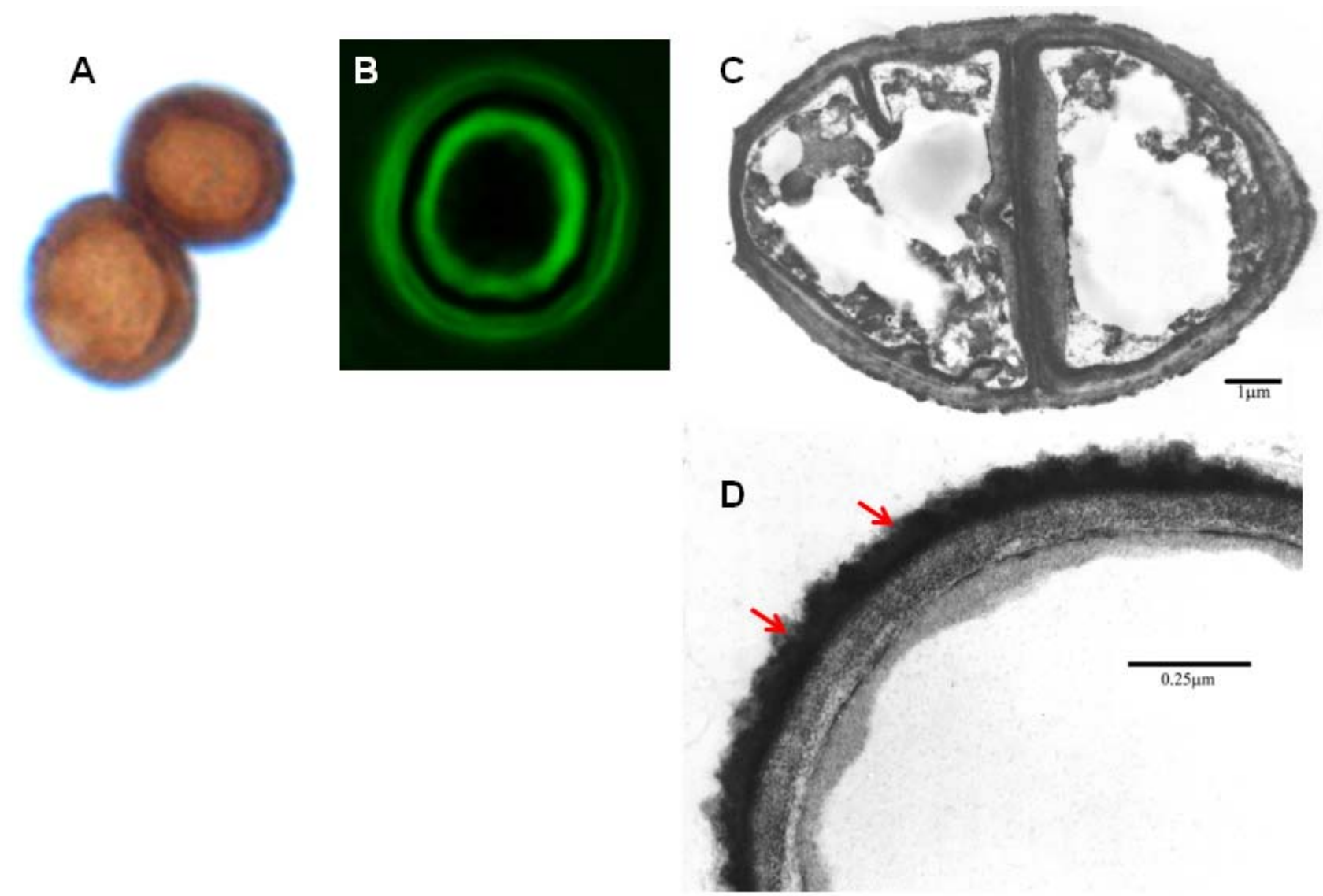

Figure 3. F. pedrosoi chlamydoconidia cells from 6-month cultures. (A) Light microscope image (1000x); (B) autofluorescent wall layers (1000x); (C) TEM of a roundish cell with longitudinal and transverse septa; (D) TEM of a wall from terminal chlamydoconidia, showing four layers with an external electrondense layer.

\section{Infection with Cells from Old Cultures}

Mouse footpads were monitored over the course of seven months, while animals maintained a stable and chronic infection process. At 4 to 5 days post-infection, animals developed a small inflammatory response on their footpad. By the end of the first month, we noted footpad swelling, particularly in mice inoculated at two sites. The swelling lasted for two months, and it acquired a firm consistency. After five months, several animals that were inoculated in two footpads developed foot hyperkeratosis. All animals infected showed progressive inflammatory process of footpads in the early post-infection period (Figure 4). However, animals inoculated in two sites exhibited more swelling, chronicity and stability of the infectious process. Eight mice inoculated at one site healed after five months. Infection metastasis to other organs did not occur. In general, a small number of sclerotic bodies (3 to 4 
cells/optical field) were observed in lesions during direct examination (Figure 5) and in anatomopathological sections (Figure 6). Histopathological findings revealed tissue hyperplasia, granulomas and proliferation of pseudoepitheliomatous cells. Additionally, observed lesions presented microabscesses surrounded by foamy macrophages with polymorphonuclear leukocyte (PMN) infiltration, and encapsulated by fibroblasts. Rare eosinophils and lymphocytes were found. Neutrophils were around and inside microabscesses. Granulomas of mice inoculated at one site presented more PMN infiltration than those of animals inoculated at two sites, suggesting that the migration and action of these cells at the infection site may be important for the infection control. Viable fungal cells were recovered from 18 animals $(90 \%)$ injected at two sites and from seven animals (35\%) infected at one site.

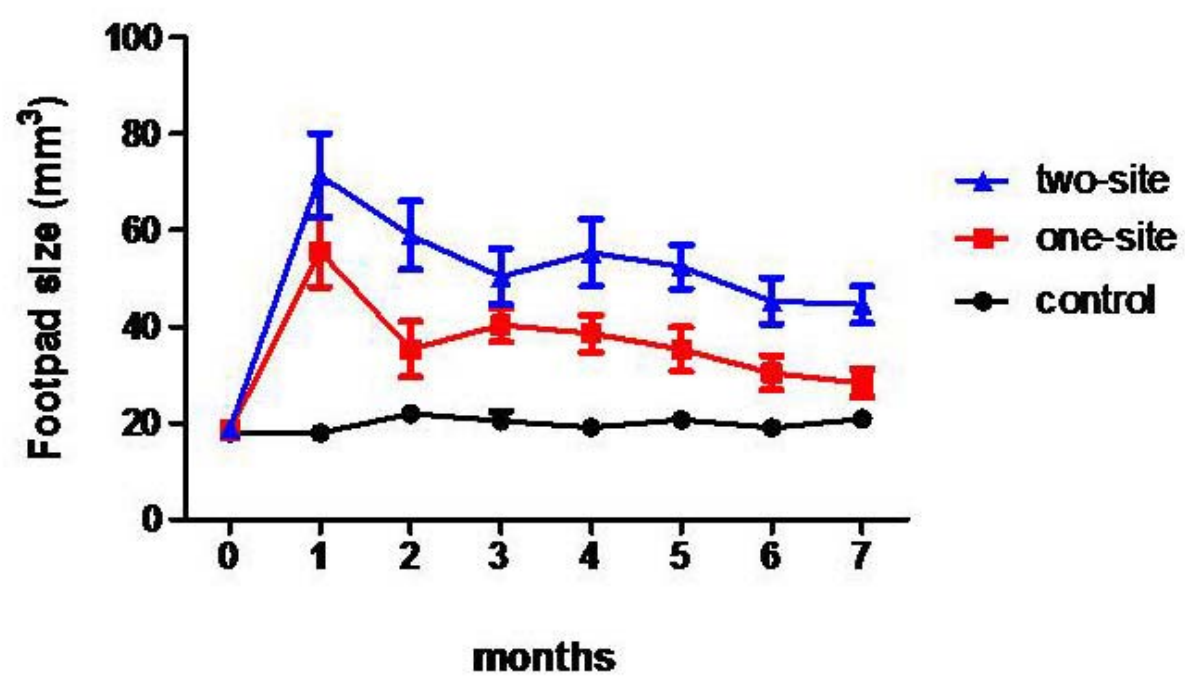

Figure 4. Kinetics of lesions from BALB/c mice that were subcutaneously infected with aged inocula of $F$. pedrosoi at one (squares, red) and two footpads (triangles, blue). The control group was treated with $50 \mu \mathrm{L}$ of PBS (circles, black). Footpads of mice were measured every 30 days for seven months after inoculation. Animals infected at two sites had strong swelling and a more chronic infectious process. Data are shown with mean and SE values, ANOVA test, $p<0.05$. 

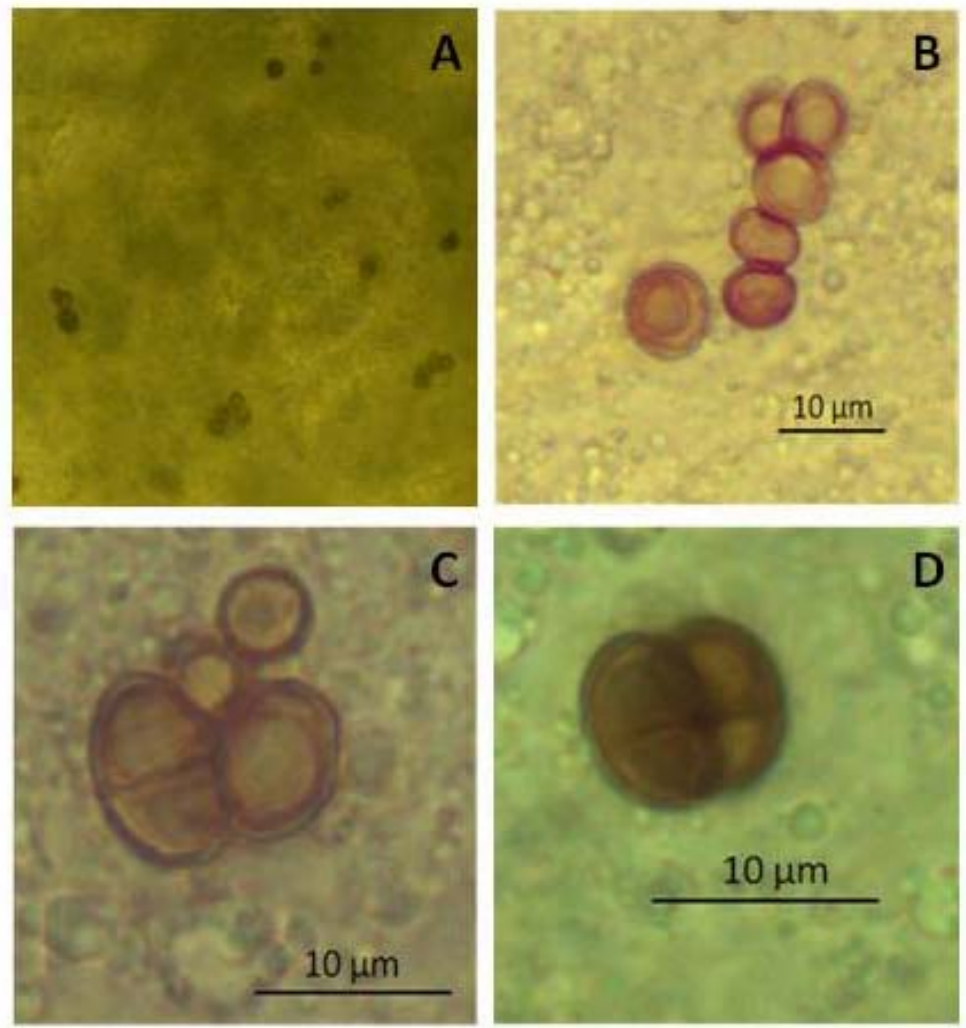

Figure 5. Sclerotic cells from footpad tissue samples obtained seven months after infection observed by direct examination; (A) 100x, (B) 400x, (C and D) 1000x. 

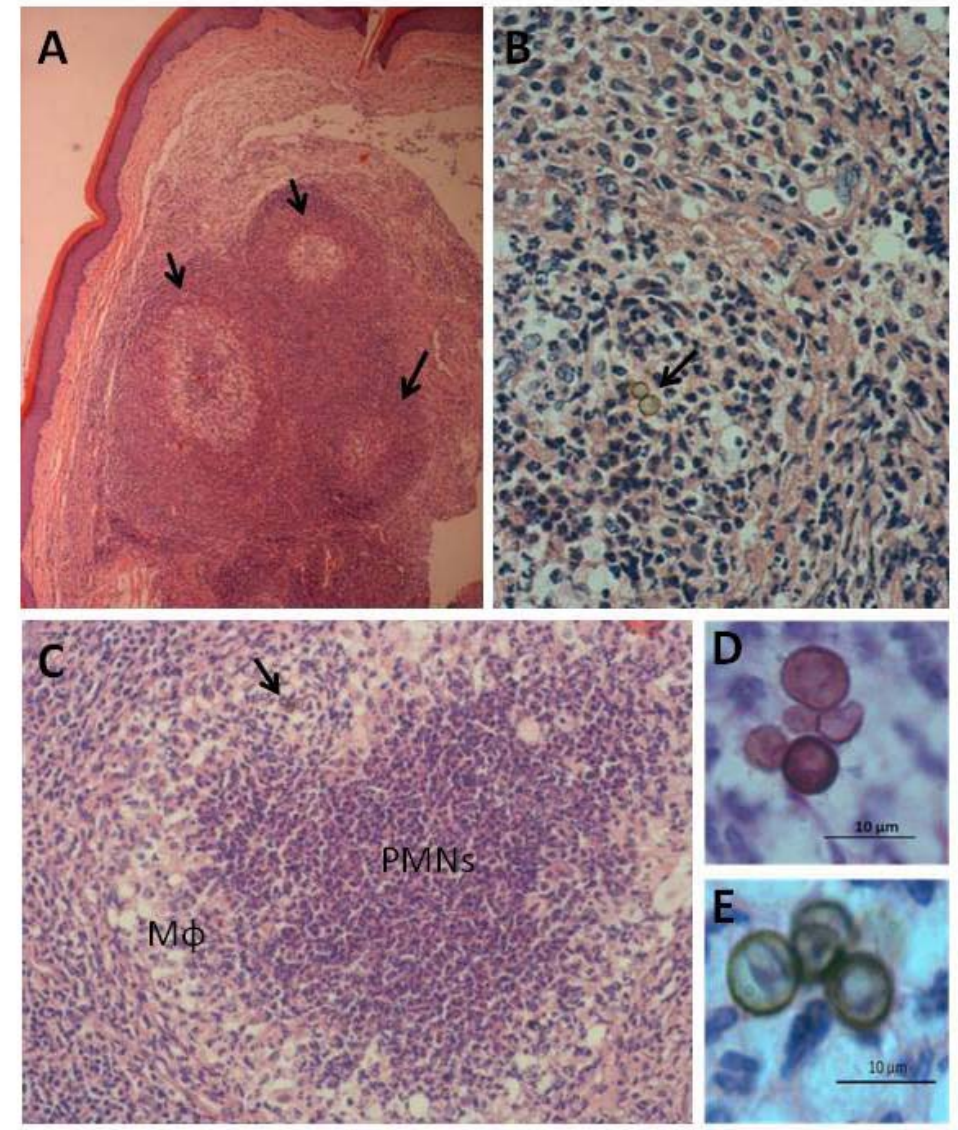

Figure 6. Photomicrography of histopathological sections from footpad tissue of animals with chronic experimental CBM infection at seven months after infection; tissue was stained with PAS. (A, arrows) Granulomatous reaction containing microabscesses with neutrophilic infiltration, foamy macrophages, low numbers of lymphocytes and eosinophils, and (B) recovery by fibroblasts. Few sclerotic cells of F. pedrosoi were found in granulomas of mice inoculated at (C) one site or (B) two sites. (C) PMN rich cellular infiltration surround by macrophages $(\mathrm{M} \varphi)$ of animal tissue infected at one site. (D and E) Sclerotic cells with diameters ranging from 5 to $10 \mu \mathrm{m}$.

(A) 40x, (B) 200x, (C) 100x, (D and E) 1000x.

*Panel $\mathbf{E}$ is a magnified view of $\mathbf{C}$ (arrow).

$M \varphi$ : macrophages, PMN: polymorphonuclear leukocytes. 


\section{DISCUSSION}

Since the discovery of CBM, a number of studies involving experimental inoculation with CBM agents have been carried out in an attempt to develop an animal model of the disease $(11-13,15,16,25)$. However, a suitable model for chronic experimental CBM has yet to be established $(4,26)$. Fonsecaea pedrosoi inoculated in various peritoneal sites caused persistent infection $(18,27)$. Suppressed host immune response in the presence of chromoblastomycotic agents may be related to the induction of a specific population of $\mathrm{T}$ cells (4). Inoculation of Leishmania major at two sites on BALB/c mice, for example, stimulated the migration of regulatory $\mathrm{T}$ cells to one of the infection sites, resulting in greater infection chronicity than that observed in animals inoculated at a single site (20). In this study, we verified that $F$. pedrosoi cells cultured for a long period of time could cause chronic infection in $\mathrm{BALB} / \mathrm{c}$ mice, especially if the inoculation occurred at more than one site. We also verified that low concentrations of aged inoculum are capable of producing a stable experimental infection, in contrast to other studies that employed a high number of $F$. pedrosoi cells to obtain acute infections $(13,15,16)$.

A variety of cellular forms of the $F$. pedrosoi strain were observed in the present study (Figure 1). The nutritional starvation in old cultures may be a reason for the abnormal fungal morphology observed in vitro. Many other dematiaceous fungi such as Alternaria alternata, Cladosporium cladosporiodes, Scytalidium lignicola, Phialophora verrucosa, P. parasitica, P. richardsiae, C. carrionii, C. boppii and Rhinocladiella aquaspersa as well as several clinical strains of $F$. pedrosoi $(n=8)$ showed high melanized forms, including chlamydoconidia and sclerotic-like cells, after culturing for longer than six months. Prominent melanization of certain fungal forms was observed in TEM as electron-dense pigments, particularly in the outer layer of the cell wall. The microbial ability to synthesize melanins can be related to virulence and pathogenicity (28).

Many pathogenic fungi have melanized forms or secrete melanin in order to increase their resistance to environmental hazards and to enable them to evade host defense mechanisms (29). However, in addition to wall coverage and melanin secretion, infective forms of CBM agents may possess additional virulence factors harmful to hosts. The transformation of dematiaceous cells into resistant forms similar to sclerotic bodies should be considered an important virulence factor. For this, meristematic forms (resistant thick-walled globose cells) found in vegetables may be 
possible precursor cells of CBM-parasitic forms. In plant hosts they can be regarded as an extremotolerant survival phase $(6,10)$.

Production of sclerotic cells in vitro results from morphological changes in hyphae and conidia of $F$. pedrosoi and Cladophialophora spp. chemically induced by growth under stress conditions $(5,6,7,30)$. Hence, the fungal changes in hostile environments could be considered a step for pre-adaptation of CBM agents to human/animal parasitism. Interestingly, several fungal forms of $F$. pedrosoi, including terminal chlamydoconidia-shaped cells, have been observed in samples collected from thorns of Mimosa pudica, reported to be a probable natural source of CBM agents (31). A significant number of roundish chlamydoconidia-shaped melaninenriched cells were observed in inocula utilized to cause animal infections in the present study. Such forms may be precursors of sclerotic cells subsequently observed at seven months after the infection. Both melanized cells and sclerotic cells had similar morphology and diameters of approximately 5 to $10 \mu \mathrm{m}$.

Effective acute cellular response in animals against $F$. pedrosoi cells from young cultures involves intense neutrophil infiltration $(11-13,17)$. In this study, however, sclerotic bodies were resistant to neutrophil killing mechanisms and macrophage phagocytosis. Sections taken from infected tissues in animals inoculated at a single site showed a higher number of neutrophils than those taken from animals inoculated at multiple sites, while several mice from the unifocal infection group healed after five months. Histopathological sections of tissue from human disease revealed hyperkeratotic pseudoepytheliomatous hyperplasia with microabscesses rich in polymorphonuclear neutrophils $(4,32)$.

According to our histological results, we detected tissue hyperplasia and granulomatous reactions with microabscesses containing central neutrophil infiltrates surrounded by foamy macrophages, sclerotic bodies inside giant cells, rare lymphocytes and eosinophils, and an external layer encapsulated by fibroblasts. We also noted additional pathological characteristics that further indicated the similarity in the disease process between our infected mice and human CBM patients, such as fibrosis, acanthosis and hyperkeratosis.

In the current investigation, experimental CBM disease with chronic outcomes was demonstrated to be associated with fungal morphology and host responses. Old cultures may represent an alternative means to obtain chlamydoconidia-shaped and well-melanized roundish cells capable of provoking a stable chronic infection 
resistant to the host response, particularly if these forms are inoculated into mice at more than one site. In the future, such F. pedrosoi forms may be a suitable method for investigating infections in vivo, although the time required can be rather long, at least ten months.

\section{ACKNOWLEDGEMENTS}

We thank Professor Maria Regina Regis Silva, Department of Pathology (UNIFESP), for her help with histopathological analyses. This study was carried out with financial support of CNPq. 


\section{REFERENCES}

1. Queiroz-Telles F, Esterre P, Perez-Blanco M, Vitale RG, Salgado CG, Bonifaz A. Chromoblastomycosis: an overview of clinical manifestations, diagnosis and treatment. Med Mycol. 2009;47(1):3-15.

2. López Martínez R, Méndez Tovar LJ. Chromoblastomycosis. Clin Dermatol. 2007;25(2):188-94.

3. Vitale RG, de Queiroz Telles F, de Hoog S. The dark world of black fungi: a major area of concern. Preface. Med Mycol. 2009;47(1):1.

4. Esterre P, Richard-Blum S. Chromoblastomycosis: new concepts in physiopathology and treatment. J Mycol Med. 2002;12(1):21-4.

5. da Silva MB, da Silva JP, Sirleide Pereira Yamano S, Salgado UI, Diniz JA, Salgado CG. Development of natural culture media for rapid induction of Fonsecaea pedrosoi sclerotic cells in vitro. J Clin Microbiol. 2008;46(11):3839-41.

6. Badali H, Gueidan C, Najafzadeh MJ, Bonifaz A, van den Ende AH, de Hoog GS. Biodiversity of the genus Cladophialophora. Stud Mycol. 2008;61(1):175-91.

7. Mendoza L, Karuppayil SM, Szaniszlo PJ. Calcium regulates in vitro dimorphism in chromoblastomycotic fungi. Mycoses. 1993;36(5-6):157-64.

8. De Hoog GS, Queiroz-Telles F, Haase G, Fernandez-Zeppenfeldt G, Attili Angelis D, Gerrits Van Den Ende $A H$, et al. Black fungi: clinical and pathogenic approaches. Med Mycol. 2000;38 (Suppl 1):243-50.

9. Zeppenfeldt G, Richard-Yegres N, Yegres F. Cladosporium carrionii: hongo dimórfico en cactáceas de la zona endémica para la cromomicosis en Venezuela. Rev Iberoam Micol. 1994;11(3):61-3.

10. de Hoog GS, Nishikaku AS, Fernandez-Zeppenfeldt G, Padín-González C, Burger $\mathrm{E}$, Badali $\mathrm{H}$, et al. Molecular analysis and pathogenicity of the Cladophialophora carrionii complex, with the description of a novel species. Stud Mycol. 2007;58(1):219-34.

11. Polak A. Experimental infection of mice by Fonsecaea pedrosoi and Wangiella dermatitidis. Sabouraudia. 1984;22(2):167-9.

12. Walsh TJ, Dixon DM, Polak A, Salkin IF. Comparative histopathology of Dactylaria constricta, Fonsecaea pedrosoi, Wangiella dermatitidis, and Xylohypha bantiana in experimental phaeohyphomycosis of the central nervous system. Mykosen. 1987;30(5):215-25. 
13. Kurita N. Cell-mediated immune responses in mice infected with Fonsecaea pedrosoi. Mycopathologia. 1979;68(1):9-15.

14. Nishimura K, Miyaji M. Defense mechanisms of mice against Fonsecaea pedrosoi infection. Mycopathologia. 1981;76(3):155-66.

15. Al-Doory Y. Chromomycosis. Missoula: Mountain Press Publishing Company; 1972. p. $1-50$.

16. Kurup PV. Pathogenicity of Phialophora pedrosoi. Mykosen. 1971;14(1):41-4.

17. Gugnani HC, Obiefuna MN, Ikerionwu SE. Studies on pathogenic dematiaceous fungi, II. Pathogenicity of Fonsecaea pedrosoi and Phialophora verrucosa for laboratory mice. Mykosen. 1986;29(11):505-15.

18. Cardona-Castro N, Agudelo-Flórez P. Development of a chronic chromoblastomycosis model in immunocompetent mice. Med Mycol. 1999;37(2):813.

19. Belkaid Y, Piccirillo CA, Mendez S, Shevach EM, Sacks DL. CD4+CD25+ regulatory $\mathrm{T}$ cells control Leishmania major persistence and immunity. Nature. 2002;420(6915):502-7.

20. Mendez S, Reckling SK, Piccirillo CA, Sacks D, Belkaid Y. Role for CD4(+) CD25(+) regulatory $T$ cells in reactivation of persistent leishmaniasis and control of concomitant immunity. J Exp Med. 2004;200(2):201-10.

21. Reynolds ES. The use of lead citrate at high $\mathrm{pH}$ as an electron-opaque stain in electron microscopy. J Cell Biol. 1963;17:208-12.

22. Committee on Guidelines for the Use of Animals in Neuroscience and Behavioral Research. Guidelines for the care and use of mammals in neuroscience and behavioral research. Washington: The National Academies Press; 2003. Available from:http://grants.nih.gov/grants/olaw/National_Academies_Guidelines_for_Use_and_Care.pdf.

23. National Advisory Committee for Laboratory Animal Research. Guidelines on the care and use of animals for scientific purposes. Washington: National Advisory Committee for Laboratory Animal Research; 2004. Available from: http://www.ava.gov.sg/NR/rdonlyres/C64255C0-39334EBCB8694621A9BF682/8338/Attach3_Animalsfor ScientificPurposes.

24. Canadian Council on Animal Care. Guide to the care and use of experimental animals. Canada: Canadian Council on Animal Care; 1993. Available from: http://www.ccac.ca/ en/CCAC_Programs/Guidelines_Policies/PDFs/ExperimentalAnimals_GDL.pdf. 
25. Ahrens J, Graybill JR, Abishawl A, Tio FO, Rinaldi MG. Experimental murine chromomycosis mimicking chronic progressive human disease. Am J Trop Med Hyg. 1989;40(6):651-8.

26. Esterre P, Queiroz-Telles F. Management of chromoblastomycosis: novel perspectives. Curr Opin Infect Dis. 2006;19(2):148-52.

27. Cardona-Castro N, Agudelo-Flórez P, Restrepo-Molina R. Chromoblastomycosis murine model and in vitro test to evaluate the sensitivity of Fonsecaea pedrosoi to ketoconazole, itraconazole and saperconazole. Mem Inst Oswaldo Cruz. 1996;91(6):779-84.

28. Nosanchuck JD, Casadevall A. The contribution of melanin to microbial pathogenesis. Cell Microbiol. 2003;5(4):203-23.

29. Jacobson E. Pathogenic roles for fungal melanins. Clin Microbiol Rev. 2000;13(4):708-17.

30. da Silva JP, Alviano DS, Alviano CS, de Souza W, Travassos LR, Diniz JA, et al. Comparison of Fonsecaea pedrosoi sclerotic cells obtained in vivo and in vitro: Ultrastructure and antigenicity. FEMS Immunol Med Microbiol. 2002;33(1):63-9.

31. Salgado CG, da Silva JP, Diniz JA, da Silva MB, da Costa PF, Teixeira C, et al. Isolation of Fonsecaea pedrosoi from thorns of Mimosa pudica, a probable natural source of chromoblastomycosis. Rev Inst Med Trop São Paulo. 2004;46(1):33-6.

32. Uribe F, Zuluaga Al, Leon W, Restrepo A. Histopathology of chromoblastomycosis. Mycopathologia. 1989;105(1):1-6. 